\title{
The real world: What does it mean? Do I belong to it?
}

\author{
Manuel J. Antunes, MD, PhD, DSc
}

\author{
From the Center of Cardiothoracic Surgery, University Hospital and Faculty of Medicine, Coimbra, Portugal. \\ Disclosures: Author has nothing to disclose with regard to commercial support. \\ Received for publication Aug 23, 2017; accepted for publication Aug 26, 2017; available ahead of print Sept 21, \\ 2017. \\ Address for reprints: Manuel J. Antunes, MD, PhD, DSc, Center of Cardiothoracic Surgery, Centro Hospitalar \\ Universitário de Coimbra, Praceta Professor Mota-Pinto, 3000-075 Coimbra, Portugal (E-mail: antunes.cct. \\ chuc@sapo.pt). \\ J Thorac Cardiovasc Surg 2017;154:1913-4 \\ $0022-5223 / \$ 36.00$ \\ Copyright (C) 2017 by The American Association for Thoracic Surgery \\ http://dx.doi.org/10.1016/j.jtcvs.2017.08.073
}

When I see (and it happens quite often) the expression "real-world outcomes" in the title of a scientific article, I wonder what real world really means. What is there beyond the "real world"? Antonyms to real are imaginary, legendary, mythical, and so on. It appears to me that the expression real world is frequently used to justify small series or worse results in comparison with those produced by "out-of-this-world" institutions and teams, with series and outcomes that are out of reach of most of us "common mortals."

This is certainly not the case of the article, "Real-world Outcomes of Surgery for Native Mitral Valve Endocarditis," published in this issue of the Journal by Toyoda and colleagues, ${ }^{1}$ the Mount Sinai group led by David Adams. In this work, Toyoda and colleagues ${ }^{1}$ compare short- and long-term outcomes of 1970 patients who underwent isolated primary mitral valve repair $(n=367$; $19 \%$ ) or replacement for active infective endocarditis between 1998 and 2014. They certainly do not belong to the "real world," even if the study cohort includes patients operated on in 146 hospitals from the states of New York and California, equally distributed, and a large number of surgeons (264 in New York State alone), many of whom had single-digit experiences during a 12-year period (the number of operations per surgeon ranged from 1 to 39 cases). And although this is difficult to ascertain from the article, there was obviously a significant pattern of referral of patients to reference centers in both states, because it is obvious that most patients were operated on in only a few institutions.

I therefore dislike the title of the article, but that is where my objections end. This is, undoubtedly, an important and very informative study, which will certainly attract the attention of the readers of the Journal.

Several important messages can be derived from this work. First, and most important, the outcomes appeared to be better in patients subjected to mitral valve repair, with regards to early and late mortality and recurrence of infection. This could be surprising, even for the staunch mitral valve repair surgeon I believe I am, if one has in mind the median

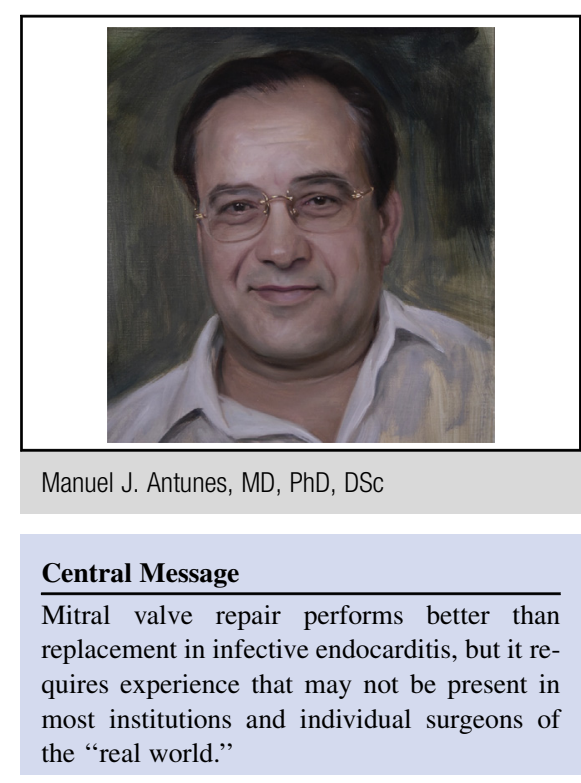

See Article page 1906.

of 2 cases per surgeon, and a repair rate ranging from 0 to $84 \%$ (median $14.3 \%$ ) among surgeons who operated on more than 5 endocarditis cases. From this point of view, experience would appear to play little role in such series. And there was at least one surgeon who had a 100\% repair rate (one out of one patient!).

Second, the rate of repair almost doubled from 1998 $(10.7 \%)$ to $2014(19.4 \%)$. The current guidelines clearly indicate that "valve repair is favored whenever possible, particularly when IE affects the mitral or tricuspid valve without significant destruction."2 The message is obviously getting there, but there was a great heterogeneity of the patient population among centers and individual surgeons with regard to the severity and the microbiology of the infection. Also, there is no information about the time evolution of the disease (acute vs chronic and active vs healed). Although this is not generally accepted, I am profoundly convinced that at least a relative control of the infectious process by adequate antibiotic therapy, if the hemodynamics and the type of microorganism permit, favors repair. In the current series, patients undergoing mitral repair were less likely to have an active virulent organism.

Third, the cumulative incidence of reoperation at 1 year was significantly higher $(9.2 \%$ vs $2 \%)$ for patients operated on by surgeons with an annual mitral volume of fewer than 25 cases (the majority, judging by the median of 2 cases). 
These results thus may be heavily distorted by the great disparity in institutional and individual surgeons' volumes and experiences. Again, this tells much about the "real world" classification of this series!

Fourth, as Toyoda and colleagues ${ }^{1}$ state, "The superior freedom from recurrent endocarditis may be the primary rationale for favoring repair over replacement where feasible." I agree, but the question to be answered is this: In these circumstances, does this render a lesser than perfect result after repair acceptable, which is not the case for noninfectious disease? Probably not, but this has never been tested, although detailed analysis of patient subsets may give us a clue.

Finally, and in conclusion, I could not agree more with Toyoda and colleagues ${ }^{1}$ when they claim that "these patients are rarely true surgical emergencies." A repair rate lower than $20 \%$ is probably too low. There are centers claiming 50\% repair rates and higher. ${ }^{3}$ Given the results highlighted by the study of Toyoda and colleagues, ${ }^{1}$ this is an area where there is an even greater justification for the establishment of reference centers that concentrate both institutional and surgeon-specific expertise. Risk scoring systems for outcomes for endocarditis surgery have been developed, which may help in decision making. ${ }^{4}$

\section{References}

1. Toyoda N, Itagaki S, Egorova NN, Tannous H, Anyanwu AC, El-Eshmawi A, et al. Real-world outcomes of surgery for native mitral valve endocarditis. J Thorac Cardiovasc Surg. 2017; 154:1906-12.e9.

2. Habib G, Lancellotti P, Antunes MJ, Bongiorni MG, Casalta JP, Del Zotti F, et al. 2015 ESC guidelines for the management of infective endocarditis: The Task Force for the Management of Infective Endocarditis of the European Society of Cardiology (ESC). Endorsed by: European Association for Cardio-Thoracic Surgery (EACTS), the European Association of Nuclear Medicine (EANM). Eur Heart J. 2015;36:3075-128.

3. de Kerchove L, Price J, Tamer S, Glineur D, Momeni M, Noirhomme P, et al. Extending the scope of mitral valve repair in active endocarditis. J Thorac Cardiovasc Surg. 2012;143:S91-5.

4. Gaca JG, Sheng S, Daneshmand MA, O'Brien S, Rankin JS, Brennan JM, et al. Outcomes for endocarditis surgery in North America: a simplified risk scoring system. J Thorac Cardiovasc Surg. 2011;141:98-106.e1-2. 